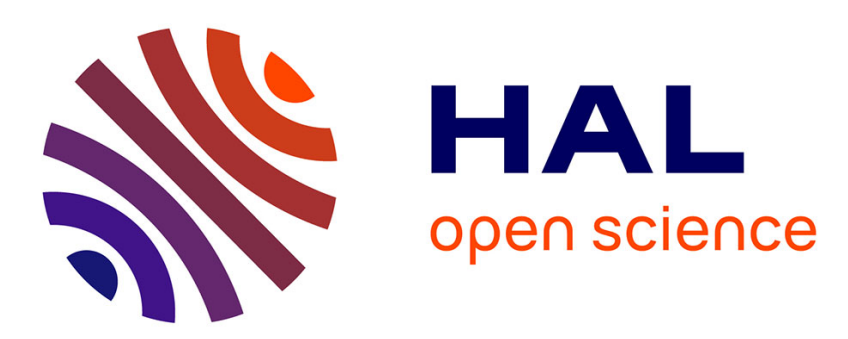

\title{
Design of functional nanostructured materials using supercritical fluids
}

François Cansell, Cyril Aymonier

\section{To cite this version:}

François Cansell, Cyril Aymonier. Design of functional nanostructured materials using supercritical fluids. Journal of Supercritical Fluids, 2009, 47 (3), pp.508-516. 10.1016/j.supflu.2008.10.002 . hal00353893

\section{HAL Id: hal-00353893 \\ https://hal.science/hal-00353893}

Submitted on 15 Feb 2012

HAL is a multi-disciplinary open access archive for the deposit and dissemination of scientific research documents, whether they are published or not. The documents may come from teaching and research institutions in France or abroad, or from public or private research centers.
L'archive ouverte pluridisciplinaire HAL, est destinée au dépôt et à la diffusion de documents scientifiques de niveau recherche, publiés ou non, émanant des établissements d'enseignement et de recherche français ou étrangers, des laboratoires publics ou privés. 


\title{
Design of functional nanostructured materials using supercritical fluids
}

\author{
F. Cansell, C. Aymonnier
}

Published in The Journal of Supercritical Fluids 2009, vol. 47, n 3, p. 508-516.

\begin{abstract}
This paper describes how the specific properties of supercritical fluids have been exploited in the last 5 years for synthesizing functional nanostructured materials, especially in the field of inorganic and hybrid materials. It is shown that control of the physicochemical properties of nanomaterials (size, morphology, structure and composition) as "nanobricks" is achieved by choosing specific operating parameters. Next, the structure formation of these "nanobricks" is discussed in order to design advanced nanostructured materials.

This is illustrated with the design of nanorods, nanowires, conformational films, core-shell structure, supported nanoparticles, polymer impregnation with nanoparticles and organic coating of particles. The associated properties for applications in many interesting fields, such as catalysis, electronics, energy, optics, etc. are reported.
\end{abstract}

\section{Introduction :}

The use of supercritical fluids in the field of Materials Science starts from the beginning of the 1990s and is closely linked to the rise of Nanosciences and Nanotechnologies.

The most important feature, within the supercritical region, is that there is no phase boundary between the gas and liquid phases. This means that there is continuity in the thermophysical properties of the fluid between the gas and liquid states.

The consequence is that supercritical fluids have properties which are "hybrids" of those normally associated with liquids and gases and which are continuously adjustable from gas to liquid with small pressure and temperature variations. Thus, the viscosities and diffusivities are similar to those of the gas while the density is closer to that of a liquid. Furthermore, surface tension vanishes above the critical point of the fluid; this is of particular interest in surface and interface chemistries. It is this combination of properties which has continued to fascinate chemists for over 150 years that has led to the current scientific and industrial interests in supercritical fluids.

Aside from these specific properties, a mention must be made on the use of supercritical fluids for sustainable development and for the development of green processes [1] and [2]. Sustainable development is an old concept from the 1970s that was born at the first conference of Stockholm in 1972. From this event, the word "sustainable" has become more and more important in the everyday life of people, especially of researchers, engineers, etc. Supercritical fluid as a green or sustainable technology means that it brings improvements in economy, society and environment.

Since the 1990's, studies and development efforts have been focused on the synthesis of nanomaterials using supercritical fluids; this has been reviewed several times over the last 5 years [3], [4], [5] and [6].

This article describes how the specific properties of supercritical fluids have been exploited in the last 5 years for synthesizing functional nanostructured materials, especially in the field of inorganic and hybrid materials, from the knowledge acquired on the formation of nanomaterials. Fig.1 illustrates, schematically, the outline of this paper showing how to get functional nanostructured materials starting from a metal precursor. We will discuss the new results obtained in the formation of inorganic nanomaterials acting as "nanobricks" to build hybrid nanostructured materials and advanced inorganic nanostructured materials with specific properties for applications in many interesting fields, such as catalysis, electronics, energy, optics, etc. 


\section{Inorganic nanomaterials design :}

This first part is devoted to the description of original results published in the last years on the synthesis of inorganic nanomaterials using supercritical fluids. It is shown how the control of the physicochemical properties of nanomaterials is achieved by choosing specific operating parameters, especially the control of material nature, composition and the crystallinity rate of nanopowders.

\subsection{Control of material nature}

The choice of solvent has a great influence on the chemical nature of materials, as already demonstrated by the syntheses of metal copper in $\mathrm{CO}_{2}$ (Fig. 2a) or copper nitride in supercritical ammonia [5] and [7]. $\mathrm{CO}_{2}$ is an inert solvent, whereas $\mathrm{NH}_{3}$ reacts with the metal atoms to produce nitrides. The transformation of metal precursors in supercritical ammonia can conduct to the formation of nitrides in a controlled manner at relatively low temperature and pressure in comparison with other classical methods [8]. Beyond the case of copper, metal nitride formation does not depend only on the solvent choice but also on the nature of the metal. In fact, three different behaviors can be observed: nitride or oxinitride formation $\left(\mathrm{Cu}_{3} \mathrm{~N}, \mathrm{Ni}_{3} \mathrm{~N}\right.$ (Fig. 2b) and $\left.\mathrm{Co}_{2} \mathrm{~N}\right)$, formation of a mixture of both oxide/nitride $\left(\mathrm{Fe}_{2} \mathrm{O}_{3} / \mathrm{Fe}_{4} \mathrm{~N}\right.$ and $\left.\mathrm{Cr}_{2} \mathrm{O}_{3} / \mathrm{Cr}_{2} \mathrm{~N}\right)$ and oxide formation $\left(\mathrm{Ga}_{2} \mathrm{O}_{3}, \mathrm{TiO}_{2}\right.$ and $\left.\mathrm{Al}_{2} \mathrm{O}_{3}\right)$. These results can be explained by looking at the affinity of these different metals with oxygen, which can be quantified from an Ellingham diagram of oxide formation. Generally, this diagram is established at atmospheric pressure but can be used under our pressure conditions. On the one hand, metals for which oxide formation is thermodynamically unfavorable $(\mathrm{Cu}, \mathrm{Ni}$ and $\mathrm{Co})$ tend to only give metal nitrides because the ammonolysis reaction is favored relative to the oxidation reaction of metal by the oxygen atoms dissolved in the reaction media. On the other hand, metals for which the Gibbs free energy change for oxide formation is favorable ( $\mathrm{Ti}$ and $\mathrm{Al}$ ) lead to metal oxides.

Oxide formation is also extensively studied in supercritical water providing a good reaction medium for hydrothermal processing of nanoparticles [9]. The hydrolysis of metal salts or precursors in supercritical water leads to the crystallization of hydroxide or oxide particles ( $\mathrm{AlOOH}-\mathrm{Fig}$. 2c, $\left.\mathrm{Fe}_{2} \mathrm{O}_{3}, \mathrm{Fe}_{3} \mathrm{O}_{4}, \mathrm{Co}_{3} \mathrm{O}_{4}, \mathrm{NiO}, \mathrm{TiO}_{2}, \mathrm{ZrO}_{2}, \mathrm{CeO}_{2} \ldots\right)$.

To conclude, the solvent has a strong influence on the nature of the produced materials. $\mathrm{CO}_{2}$ and $\mathrm{H}_{2} \mathrm{O}$ are the most used solvents for the formation of nanomaterials in supercritical fluids. The addition of alcohol in $\mathrm{CO}_{2}$ is currently observed to increase the solubility of reactants in the fluid system. A new trend is appearing with the study of water/alcohol mixture from a few years ago [10]. Adding alcohol to water allows the critical coordinates of the fluid system to decrease [11] and to promote crystallization (see Section 2.2).

In addition to the choice of the reaction media, there exist different operating parameters that can be adjusted to tune the characteristics of the final product, especially the size. Very few works have been performed towards the development of numerical tools to predict the growth of inorganic nanoparticles. As far as it is known, the simulation of the formation of inorganic nanoparticles was just investigated through two different approaches: (i) for the synthesis of oxides in supercritical water where the model predicts the size distribution of particles from the classical nucleation and growth theory (precipitation mechanism) [12] and (ii) for the synthesis of metal nanoparticles, a monodisperse mathematical model based on a two steps mechanism, coalescence and coagulation, predicts the evolution of the particle size distribution as a function of the process operating parameters [13]. The second model was validated with experimental data obtained from the synthesis of metal copper particles in a scCO$/ 2 \mathrm{EtOH}$ mixture. Good agreement is obtained between experimental and simulated data for the model with both coalescence and aggregation mechanisms taken into account. In the future, the model will be adapted for different materials and different reactors. For example, the continuous reactor could be adapted by coupling the model with a CFD program.

Regarding the promising results obtained on single cation based inorganic materials, investigations were focused on multi-cation based materials with the challenge of controlling the composition of materials.

\subsection{Control of the composition of multi-cations based materials}

Examples of research work on multi-cation based materials concerns the story around $\mathrm{Ba}_{x} \mathrm{Sr}_{1-x} \mathrm{TiO}_{3}(\mathrm{BST}, 0 \leq x \leq 1)$ from the synthesis of $\mathrm{TiO}_{2}$ [10], [14], [15] and [16]. BST is an important material used in electronics and 
telecommunications due to its dielectric properties. Well-crystallized BST nanopowders have been synthesized under supercritical conditions through a single step continuous synthesis over the entire range of composition, in the temperature range of $150-380^{\circ} \mathrm{C}$ at $26 \mathrm{MPa}$. The reactor temperature influences the powder purity, especially the $\mathrm{BaCO}_{3}$ contamination. The Ba:Ti ratio of the as-synthesized $\mathrm{BaTiO}_{3}$ governs the powder stoichiometry. This single step process avoids the long and tedious steps associated with other synthesis methods, such as washing, filtering, drying or calcining. Neither carbonate nor other secondary phases were produced, and in any case, only single-phase solid solutions were synthesized. The use of alkoxides as precursors permits the synthesis of the whole BST solid solutions of controlled composition for $0 \leq x \leq 1$. The preferred incorporation of strontium is already reported in hydrothermally synthesized BST powders and the formation of biphasic solid solutions were not observed here. The mean particle size of monocrystalline nanoparticles was found to be about $20 \mathrm{~nm}$ in the case of Sr-rich powders $\left(\mathrm{SrTiO}_{3}\right)$ and about $40 \mathrm{~nm}$ in the case of Ba-rich $\left(\mathrm{BaTiO}_{3}\right)$ powders. The ferroelectric transition temperature varied from -173 to $117^{\circ} \mathrm{C}$, suggesting that an accurate adjustment of the ferroelectric properties of the as-synthesized powders was possible. The composition $\mathrm{Ba}_{0.7} \mathrm{Sr}_{0.3} \mathrm{TiO}_{3}$ appears to be a promising material considering its dielectric characteristics with a transition temperature, $T_{\mathrm{c}}$, close to room temperature. This important study on the synthesis of multi-cation based materials and BST has opened the investigation field for the use of water/alcohol mixture as reaction media. In fact, work in this area has shown that adding ethanol to water could promote the crystallization of the materials being used by reducing the critical coordinate of the reaction media. There is little work interested in doing chemistry with supercritical water/alcohol mixtures. New neodymium-nickel crystalline precursors have been formed in an ethanol/water supercritical mixture [17]. Fig. 3 shows the difference between the X-ray diffraction patterns obtained in water (Fig. $3 a-\operatorname{mixture~} \mathrm{Nd}(\mathrm{OH})_{3}$ and $\mathrm{Ni}(\mathrm{OH})_{2}$ ) and in ethanol/water with a molar ratio 90/10 (Fig. 3b - new structure). With this precursor it is possible to have a method for the development of intermediate temperature SOFCs by the direct formation of the cathode material $\mathrm{Nd}_{2} \mathrm{NiO}_{4+\delta}$ on the electrolyte with a short firing step $(3 \mathrm{~h})$ at $1100{ }^{\circ} \mathrm{C}$. It is important to note that $\mathrm{Nd}_{2} \mathrm{NiO}_{4+\delta}$ is a "difficult to make" compound that currently cannot be made directly or efficiently via conventional processing methods. Singlephase yttrium aluminium garnet (YAG) has also been produced by the rapid hydrolysis and dehydration of $\mathrm{Al}^{3+}$ and $\mathrm{Y}^{3+}$ salts in water/ethanol mixtures [18]. YAG possesses a high efficiency for energy transfer and is resistant to radiation changes, which make it ideal for laser lenses.

Formation of oxides in an ethanol/water supercritical mixture seems to be very promising since control of the nature of the chemical reaction is accessed via the initial ethanol/water ratio, allowing modifications of the powders properties, such as crystallographic structure, morphology and surface area.

\subsection{Crystallinity control}

The control of the crystallinity of nanopowders (amorphous, amorphous/crystalline or crystalline) again shows an interest for synthesis in supercritical fluids over the more conventional routes.

Recently, supercritical fluids have been used to prepare alumina powders. Alumina is one of the most widely used oxide ceramic materials. For this reason, the challenge remains to have a controlled synthesis of the alumina nanopowders which enables cost reduction in softening sintering conditions, a method used to control of the crystallinity of the alumina starting powder.

The supercritical fluids route is a versatile technique which allows the tuning of the crystallinity of the obtained powders by a simple modification of the fluid's nature [19]. Amorphous or boehmite alumina could be successfully synthesized using either $\mathrm{CO}_{2}$ /ethanol or $\mathrm{H}_{2} \mathrm{O}$ /ethanol mixtures, respectively (Fig. 4). The two powders present very different morphologies as shown in Fig. 4. The result is a different sintering path for the alumina starting material. It has been established that the alumina formed in $\mathrm{CO}_{2}$ /ethanol exhibits a significant decrease of the $\mathrm{y}-\mathrm{Al}_{2} \mathrm{O}_{3} \rightarrow \mathrm{a}-\mathrm{Al}_{2} \mathrm{O}_{3}$ transition temperature $\left(-150^{\circ} \mathrm{C}\right)$, resulting in a lower densification temperature $\left(-80^{\circ} \mathrm{C}\right)$. This temperature decrease is very interesting regarding the cost reduction of the sintering process.

Regarding what was presented in the previous section on the preparation of ultra-fine $\mathrm{BaTiO}_{3}$ powder under supercritical conditions, the water to ethanol ratio also influences the $\mathrm{BaTiO}_{3}$ powder crystallization. This is the one way 
to obtain a highly crystalline $\mathrm{BaTiO}_{3}$ nanopowder that is synthesized through a one-pot solvothermal process (above $90 \%$ of crystallinity, $150-380^{\circ} \mathrm{C}$ at $16 \mathrm{MPa}$ ) [10].

The key to the discovery of well-crystallized heterometallic phases is the development of in situ characterization techniques. Recently, a group published work on the reactor design for an in situ high-energy synchrotron radiation study of nanoparticle formation in supercritical fluids [20] and [21]. The results presented demonstrate that nanoparticle formation can be followed in situ by simultaneous SAXS/WAXS with high-energy synchrotron radiation.

As described in Fig. 1, by mastering the synthesis of "nanobricks" in supercritical fluids, one is given access to the design of advanced nanostructured materials with specific properties. In the next section, we review recently published results on the design of hybrid functional nanostructured materials.

\section{Organic-inorganic hybrid functional nanostructured materials :}

The use of supercritical fluids for the synthesis of organic-inorganic hybrid nanostructured materials has been developed through two main approaches depending mainly on the choice of solvent, $\mathrm{CO}_{2}$ or $\mathrm{H}_{2} \mathrm{O}$.

\subsection{Organic-inorganic hybrid functional nanostructured materials in $\mathrm{scCO}_{2}$}

$\mathrm{ScCO}_{2}$ has rarely been used for the synthesis of functionalized hybrid organic/inorganic nanoparticles, mainly due to the low solubility of many organic stabilizers in $\mathrm{ScCO}_{2}[3]$. Most of the approaches used to form stabilized nanoparticles in $\mathrm{scCO}_{2}$ depend on the solubility of the reactants in the medium similar to methods developed for chemistry in liquids.

A novel chemistry that addresses the problem of reactant solubility in $\mathrm{scCO}_{2}$ for metal nanoparticle synthesis was recently reported [22]. The organic part, amphiphilically modified dendritic polyamines, were utilized because they are synthetically well accessible with a broad range of functionalities and effectively stabilize metal nanoparticles. The deciding factor for the selection of metal precursors and functionalizing agents was not their solubility, as in most previous studies, but the desired properties of the polymer/nanoparticle hybrid.

This approach was illustrated by the synthesis of palladium and silver nanoparticles (3-5 nm) stabilized with dendritic polymers functionalized with perfluoroalkyl, perfluorooligoether, polysiloxane, non-fluorinated alkyl and oligoethylene glycol moieties. The synthesis and solubility in $\mathrm{scCO}_{2}$ of these polymers have been reported previously [23]. The nanoparticle synthesis is based on the reduction of palladium acetylacetonate $\left(\operatorname{Pd}(\mathrm{acac})_{2}\right)$ and silver acetylacetonate $(\mathrm{Ag}(\mathrm{acac}))$ with $\mathrm{H}_{2}$ in $\mathrm{scCO}_{2}$ in the presence of the dendritic polymer. This approach limits the number of steps in the preparation of functional nanoparticles which are ready for use. As a demonstration of the catalytic properties of the nanoscale polymer/particle hybrids prepared in this study, hydrogenation of cyclohexene was carried out with $\mathrm{Pd} / \mathrm{PEI}-$ CO- $\mathrm{C}_{10} \mathrm{H}_{4} \mathrm{~F}_{17}$ as a catalyst in the biphasic system trifluoroethanol/cyclohexene. Complete conversion was observed in a $2 \mathrm{~h}$ experiment, corresponding to an average turnover frequency of $10^{3} \mathrm{TO}^{-1}$. These preliminary results show that hybrid nanoparticles are active for catalysis.

Another versatile synthetic method addressing the problem of surfactant solubility in $\mathrm{scCO}_{2}$ was developed. It is capable of producing a wide variety of nanoparticles possessing tunable peripheral chemical functionalities by separating the growth and the functionalization steps (Fig. 5) [24]. This method was successfully applied to the synthesis of palladium nanoparticles capped with thiol or stabilized in an ionic liquid (IL), active in catalysis, and can be generalized for core and shells of different compositions and properties.

$\mathrm{ScCO}_{2}$ also offers the possibility to swell numerous polymer matrices; this opens the route for the nanostructure formation into polymer matrices. One of the remaining challenges in this field concerns a better understanding of the interactions between $\mathrm{CO}_{2}$ and the polymer. The method involves the impregnation of the polymer matrix with metal precursor from a $\mathrm{scCO}_{2}$ solution, followed by transforming the metal precursor. As an example, palladium impregnated Nafion membranes were synthesized via a supercritical fluid route [25]. This nanostructured material was synthesized for direct methanol fuel cell (DMFCs) applications. The Pd-impregnated Nafion membranes showed reduced methanol crossover and gave improved DMFC performance compared to that of a pure Nafion membrane. Another example concerns the preparation of polypropylene (PP)/silica composites by impregnating the PP matrix with TEOS using 
$\mathrm{scCO}_{2}$ as the swelling agent followed by the hydrolysis/condensation reaction of the TEOS confined in the polymer network [26]. The results showed that nanosized silica networks were formed and distributed uniformly in the PP matrix promoting higher tensile strength and Young's modulus than virgin PP.

Another way to use $\mathrm{CO}_{2}$ for the synthesis of organic-inorganic hybrid nanostructured materials is the anti-solvent method using $\mathrm{CO}_{2}$. This method addresses the critical issues of controlling the surface properties of inorganic materials with an organic shell, the challenge being to deposit a polymer shell with different solvation properties onto the surface of the inorganic particles and to have a good control of the thickness of the organic layer without a prefunctionalization of the surface. A method for coating silica particles $(170-550 \mathrm{~nm})$, used as a model substrates, with either a hydrophilic (polyethylene glycol) or a hydrophobic polymer (polybutadienehydroxy terminated) using a supercritical anti-solvent process (precipitation from a compressed anti-solvent) was proposed [27]. Several operating parameters were studied to precisely control the thickness of the deposited layer (from 2 to $30 \mathrm{~nm}$ ), which was characterized using TEM, FESEM, XPS, and UV-vis techniques. This work demonstrates that the supercritical anti-solvent process is a powerful method and is a good alternative to conventional coating techniques used toward the development of hybrid and/or core-shell nanomaterials for high-added value applications.

\subsection{Organic-inorganic hybrid functional nanostructured materials in $\mathrm{scH}_{2} \mathrm{O}$}

Supercritical water has specific properties one of which is low solubility of inorganics due to its low dielectric constant, which makes it well suited for the synthesis of hybrid nanoparticles. Nanocrystal formation is favored and standard organic hydrocarbon capping ligands are fully miscible and can react with the surface of nanoparticles. This concept was validated on the synthesis of copper nanoparticles $(3-15 \mathrm{~nm}$ ) stabilized with alkane-thiol ligands (1-hexanethiol) in supercritical water [28]. Techniques for in-situ surface modification in $\mathrm{scH}_{2} \mathrm{O}$ of nanoparticles with organic molecules during crystallization in continuous reactors were extensively developed as recently reviewed with the specific features of hydrothermal synthesis of organic-inorganic hybrid nanoparticles [29].

The use of other supercritical fluids at high temperature $\left(350-600^{\circ} \mathrm{C}\right.$ to crystallize highly covalent nanoparticles) has offered the possibility to synthesize materials such as silicon $(1.5-4 \mathrm{~nm})$ and germanium $(2-70 \mathrm{~nm})$ nanoparticles in supercritical hexane and octanol, where octanol is employed as a capping ligand [3].

The next section is focused on the second family of complex materials that can be developed in mastering the nucleation and growth in supercritical fluids from the "nanobrick" to advanced inorganic nanostructured materials.

\section{Advanced inorganic nanostructured materials :}

Playing with the nucleation and growth in supercritical fluids can enable the design of advanced nanostructured materials as a lego-like chemistry. We discuss the design of nanostructured materials due to: (i) the nanoengineering of material surfaces to form materials based on supported nanoparticles and nanostructured films, (ii) the replication of templates (block copolymers (BCPs) or biotemplates) and (iii) the growth of one-dimensional nanostructures.

\subsection{Nanoengineering of material surface}

The nanoengineering of material surfaces is based on the supercritical fluid chemical deposition process (SCFD - Fig. 6a), which demonstrates a route towards manufacturing multifunctional materials.

\subsubsection{Supported nanoparticles}

Supercritical fluids have been used to deposit metal nanoparticles onto a wide range of external surfaces or internal ones (inorganic porous substrates) for microelectronic, optical and catalytic applications. All the work oriented towards the formation of supported nanoparticles can be divided in two main approaches: (i) a kinetically controlled surface nanostructure formation based on a homogeneous nucleation and heterogeneous growth induced by a chemical reaction [3] and (ii) a thermodynamically controlled surface nanostructure formation based on the adsorption of metal precursor onto the substrate followed by a wide variety of precursor transformation methods [30].

Work on the decoration of silica spheres with copper nanoparticles with a tunable amount of coverage between $40 \%$ and $80 \%$ and an average particle size ranging between 5 and $17 \mathrm{~nm}$ illustrates the first approach (Fig. 6b) [31]. In 
addition, to control the size and amount of coverage, the reduction of copper precursor was performed at temperatures as low as $100^{\circ} \mathrm{C}$ without any metal catalyst. $100^{\circ} \mathrm{C}$ is a low temperature when compared to results found in the literature for copper between 200 and $250^{\circ} \mathrm{C}$. This was possible in studying the kinetics of the reduction reaction of copper precursor in different mixtures of $\mathrm{CO}_{2}$ /ethanol in the presence of $\mathrm{H}_{2}$ [32]. Using the decomposition kinetics of the precursor and based on a bi-modal process, modelling was used to simulate this kinetically controlled behavior of the surface nanostructure formation using supercritical fluids. This fundamental work was applied to develop an advanced nanostructured material for hydrogen storage [33]. Nanosized particles of Pd and microsized particles of $\mathrm{Ni}$ have been successfully deposited on the surface of $\mathrm{MgH}_{2}$ powder. The hydrogen sorption properties have been checked to be as good as the one obtained on ball milled samples even if, in the case of $\mathrm{Mg}+\mathrm{Pd}$ sample, higher reaction rates have been already reported. However, the cyclability is hugely improved with "supercritical fluid materials" due to the link between metal catalysts and $\mathrm{Mg}$ particle surface.

The second approach can be described from a study of the determination of the thermodynamics and kinetics of adsorption of a ruthenium precursor on a carbon aerogel from $\mathrm{scCO}_{2}$ by the measurement of adsorption isotherms and concentration decay curves in batch mode [34]. All the isotherms were best represented by the modified Langmuir Model and a theoretical model was developed to describe the dynamics of adsorption of the ruthenium precursor. The transformation of this adsorbed precursor by different ways (chemical reduction in a supercritical fluid with a reducing agent, chemical reduction with pure hydrogen at elevated pressure, thermal reduction in a supercritical fluid, thermal decomposition in an inert atmosphere or chemical conversion with hydrogen or air at atmospheric pressure) is conducive to the formation of nanoparticles, for example ruthenium nanoparticles on carbon aerogel [35].

Following one of these two main approaches, it has been shown that one can actively decorate the internal or external material surface. For example, the formation of noble metal nanoparticles onto carbon nanotubes (CNTs) [36] or hollow polymer nanospheres [37] or into mesoporous materials [38] for catalysis (non-exhaustive list) was done using one of these approaches.

During the same time, research has also been focused on the formation of nanostructured films.

\subsubsection{Nanostructured films}

Taking the desirable attributes of CVD and aqueous plating techniques while minimizing the disadvantages of each, chemical fluid deposition (SCFD) is also used to modify the surface properties of organic and inorganic materials. This method was first used for the synthesis of nanosized thin metal films (platinum and palladium) onto silicon wafers and polymers substrates (poly-(tetrafluoroethylene), Kapton polyimide and Anopore aluminum oxide membrane) by the reduction of appropriate metal precursors with hydrogen in $\mathrm{scCO}_{2}[39]$. The films were found to be essentially free from ligand-derived contamination and exhibited excellent conformity on patterned surfaces. The SCFD method was then expanded to deposit other metal films, including gold, rhodium, cobalt, nickel, copper or still ruthenium [40] in $\mathrm{scCO}_{2}$ by the reduction of desired precursors. High purity conformal metal oxide films were also deposited onto planar and etched silicon wafers by surface-selective precursor hydrolysis in supercritical carbon dioxide using a cold wall reactor [41]. Continuous films of $\mathrm{CeO}_{2}, \mathrm{HfO}_{2}, \mathrm{TiO}_{2}, \mathrm{Nb}_{2} \mathrm{O}_{5}, \mathrm{Ta}_{2} \mathrm{O}_{5}, \mathrm{ZrO}_{2}, \mathrm{Bi}_{2} \mathrm{O}_{3}$ between 21 and $263 \mathrm{~nm}$ thick were grown at temperatures between 250 and $300{ }^{\circ} \mathrm{C}$ using $\mathrm{CO}_{2}$ soluble precursors.

Moving from the cold wall reactor to the stirred vessel reactor permits one to design core-shell structures with the deposition of metal or oxide films onto particles. The first work in this area is from the beginning of the 21th century with the deposition of metal copper on micrometer size $\mathrm{Ni}$ and $\mathrm{SmCo}_{5}$ particles by the thermal decomposition of a copper precursor at $200{ }^{\circ} \mathrm{C}$ and $19 \mathrm{MPa}$ [3]. Recently, this method was applied at the nanometer scale with the modification of the surface properties of $\mathrm{BaTiO}_{3}$ nanoparticles with a homogeneous shell of metal oxide, amorphous alumina (Fig. 6c)

[42]. The chemistry used is the one described in Section 2.3. This alumina shell plays a great role on the sintering process of the core-shell nanoparticle with an influence on the micro/nanostructure of the ceramic and on its ferroelectric properties. This material does not allow dielectric losses above $1 \%$ and is stable with temperature. This result opens a route to produce new kinds of advanced ferroelectric materials. The same method was used to coat carbon nanotubes with metal oxide films, including $\mathrm{Ce}_{2} \mathrm{O}_{3}, \mathrm{CeO}_{2}, \mathrm{Al}_{2} \mathrm{O}_{3}$ or $\mathrm{La}_{2} \mathrm{O}_{3}[43]$. 
Part of the chemistry used to form nanostructured films can be applied to the design of advanced nanostructured materials by replication of templates.

\subsection{Replication of templates}

The use of supercritical fluids provides a direct route for high-fidelity replication of complex templates in three dimensions. Block copolymers are near ideal templates for nanostructured materials for the development of next generation devices for applications in sensing and detection arrays, energy conversion and storage catalysis, separation and microfluidics [39]. BCPs can self-assemble into ordered arrays of microdomains having dimensions on the order of $5-100 \mathrm{~nm}$. The interaction of polymers with supercritical fluids enables the replication of polymer nanostructures by phase selective deposition within the templates. In BCPs, sorption of modest amounts of SCFs does not disrupt microphase separation.

The replication of block copolymer dilated with supercritical carbon dioxide for the preparation of mesoporous organosilicate films has been demonstrated [44]. Alternatively, post-synthesis functionalization of the internal pore surfaces of mesoporous materials can modify the performance of silicate materials with respect to adsorption, wetting and catalytic properties. The long-range order in mesoporous silicas can be enhanced dramatically when the amphiphilic block copolymer templates are blended with strongly interacting homopolymers prior to precursor infusion [45]. The use of supercritical carbon dioxide allows pore size engineering with pore size, wall thickness and $d$ spacing [46]. The replication of biological organizations through a supercritical fluid route is also possible with high precision [47]. In fact, nature is one of the best models providing numerous morphological architectures from the nanometer scale upwards. For example, anatase $\mathrm{TiO}_{2}$ replicas of biological organizations, including cotton and pollen, have been fabricated. Both macro- and microscopic structures of the biotemplates are kept with a higher precision than can be obtained with wet chemistry or CVD methods. 3D-networks of native starch were also utilized as a directing template to prepare the hierarchically ordered $\mathrm{TiO}_{2}$ material [48]. The templating approach can also be one of the methods to grow 1D nanostructures.

\subsection{Growth of one-dimensional nanostructures}

Morphologies such as nanowires and nanotubes attract significant interest due to their potential applications in microelectronics, interconnections, optoelectronics and as nanoscale electronic devices. However, such applications can only be realized if the nanostructures can be manipulated and organized in a controlled fashion. This section discusses how the supercritical route allows growing one-dimensional nanostructures.

\subsubsection{Nanowires and nanorods}

One route to design nanowires and nanorods is the template approach. Mesoporous silica templates can guide the growth of bismuth nanowire arrays to obtain thermoelectric properties that could be better than bulk state-of-the-art thermoelectric materials [49].

Classical synthesis methods rely on metal particles (such as gold nanocrystals) to induce nanowires growth above the semiconductor/metal eutectic temperature. Such reaction can be carried out either in the gas phase (called vaporliquid-solid or VLS method) or in the liquid phase (called solution-liquid-solid or SLS method). A synthesis method has been developed for producing nanowires less than $10 \mathrm{~nm}$ in diameter using supercritical fluids. This process has been called fluid-liquid-solid, or FLS method, and consists of thermally degrading a precursor in a supercritical fluid rather than in a gas or liquid (VLS and SLS methods respectively). There are many studies, both past and present, investigating the formation of silicon and germanium nanowires [50], [51] and [52].

Nanowire morphology can be controlled with great flexibility using the FLS method. As an alternative to Au seeds, many different nanocrystals ( $\mathrm{Co}, \mathrm{Ni}, \mathrm{CuS}, \mathrm{Mn}, \mathrm{Ir}, \mathrm{MnPt}_{3}, \mathrm{Fe}_{2} \mathrm{O}_{3}$, and $\mathrm{FePt}$ ) were explored as seeds for $\mathrm{Si}$ and $\mathrm{Ge}$ nanowire synthesis to develop a more general understanding of the role of the seed particles in the nanowire growth process [53]. Of the nanocrystals studied, Co gave the highest yield and quality for both $\mathrm{Si}$ and Ge nanowires, rivaling Au-seeded reactions. The FLS process was also used to produce gallium arsenide nanowires and gallium phosphide nanowires. In each case, the FLS process proves to be an acceptable method of synthesizing single-crystal semiconductor nanowires. Compared to VLS synthesis, this process offers more flexibility in designing the characteristics of a given 
material which results in higher yields and provides a wide range of possibilities for in-situ doping and chemical surface modification. These non-templated nanowires have been isolated and utilized to fabricate various nanowire devices, including field-effect transistors, integrated logic gates, memory devices, nanolasers and photodetectors. The integration of these nanostructures into nanowire-based devices has been achieved either by post-synthesis assembly or by "in-place" Au-seeded growth on different substrate. Channeled templates, such as anodic alumina membranes (AAMs), can be utilized to host, isolate and guide the growth of one-dimensional nanostructures [54]. This new method couples the Au-seeded and confined growth of 1D Ge nanostructures with controlled crystalline structure and electrical properties within the channel of AAMs.

\subsubsection{Carbon nanotubes}

Like nanowires and nanorods, carbon nanotubes exhibit a variety of unique properties. Their potential applications, such as their use in superconductors and magnetic recording devices, have led to widespread efforts to improve their synthesis. Gas phase synthesis results in low yields and poor crystallinity, while the high temperature required for the process can be a limitation for its use on a large scale. As an alternative, supercritical fluids have been used to prepare well-crystallized CNTs during the last 5 years [55]. Carbon dioxide was used as the carbon source in a relatively low temperature process, and lithium metal was used as a reducing agent. Typical operating conditions were $550{ }^{\circ} \mathrm{C}$ and $70 \mathrm{MPa}$. Compared with $\mathrm{CO}_{2}$ gas, $\mathrm{scCO}_{2}$ enhances the adsorption of carbon dioxide on the surface of lithium and therefore facilitates and accelerates the electron transfer process. Large amounts of CNTs were produced which had a diameter of $55 \mathrm{~nm}$ and were more than one micrometer in length, without the use of a catalyst and in relatively mild and cost effective reaction conditions. A similar approach was recently used to produce multiwalled carbon nanotubes (MWNTs) in supercritical toluene [56]. The concept was to take advantage of pressure effects to lower the high temperatures usually required to synthesize CNTs. In this process, supercritical toluene served both as the carbon source for nanotube growth, and as the reaction medium. Ferrocene, iron or platinum iron nanocrystals were used as catalysts in this process. These catalyst particles were always observed at the tip of the MWNTs. The temperature and the seed particle size (iron particles) appear to be the most significant parameters in product quality. The optimum temperature was found to be $600{ }^{\circ} \mathrm{C}$, while above this temperature neither filaments nor nanotubes were formed. These studies demonstrated that the size of the seed particle is a key parameter for the formation of CNTs.

Recently, supercritical carbon monoxide was chosen as the carbon source as it has been successfully used as a gaseous reactant by the HiPco (high pressure $\mathrm{CO}$ ) process [57]. The high concentration of supercritical carbon monoxide used in the reactor (working at $750^{\circ} \mathrm{C}$ ) results in high yield of nanotubes. The diameters of the MCNTs synthesized ranged from 10 to $20 \mathrm{~nm}$ with lengths of several tens of micrometers.

\section{Conclusion :}

Materials Science demands efficient methods of synthesizing materials with controlled size, morphology, composition and structure. By using supercritical fluids as a reaction media, material characteristics can be successfully tuned and improved, thus meeting these requirements.

This paper describes how the specific properties of supercritical fluids have been exploited for synthesizing functional nanostructured materials from the structure formation of "nanobricks". In the last years, interesting results were published showing a more controlled synthesis of these "nanobricks". For example, the formation of oxides in an ethanol/water supercritical mixture seems to be very promising since control of the nature of the chemical reaction is accessed via the initial ethanol/water ratio, allowing modifications of the powders properties, such as nature, crystallographic structure, composition, morphology and surface area. By mastering of the synthesis of "nanobricks" in supercritical fluids, we are given access to the design of advanced nanostructured materials with specific properties. This was illustrated with the design of nanorods, nanowires, conformational films, core-shell structures, supported nanoparticles, polymer impregnation with nanoparticles and organic coating of particles. The advanced nanostructured 
materials exhibit interesting properties for applications in many interesting fields, such as catalysis, electronics, energy and optics.

However, more research is required on most of the methods described in this paper from both a fundamental and applied point of view. To start, the development of multi-scale models from the understanding of interactions solutesolvent in complex chemical systems to the nucleation and growth of particles linked to kinetics and fluid dynamics is necessary. Secondly, the ability of the methods described need to be evaluated for us on a larger scale. In addition, investigations on nanomaterial handling are necessary for technological and security considerations.

We expect that the shift to supercritical fluid technology for material processing in industry will be achieved in the near future by combining economical efficiency and sustainable development.

\section{References :}

1. C. Aymonier, A. Erriguible, A. Loppinet-Serani, F. Cansell. Processes using supercritical fluids: a sustainable approach for the design of functional Nanomaterials. Int. J. Chem. Reactor Eng., 5 (2007), p. A77.

2. J.A. Dahl, B.L.S. Maddux, J.E. Hutchison. Toward greener nanosynthesis. Chem. Rev., 107 (2007), p. 2228.

3. C. Aymonier, A. Loppinet-Serani, H. Reverón, Y. Garrabos, F. Cansell. Review of supercritical fluids in inorganic materials science. J. Supercrit. Fluids, 38 (2006), p. 242.

4. E. Reverchon, R. Adami. Nanomaterials and supercritical fluids. J. Supercrit. Fluids, 37 (1) (2006), p. 1.

5. F. Cansell, C. Aymonier, A. Loppinet-Serani. Review on materials science and supercritical fluids. Curr. Opin. Solid State Mater. Sci., 7 (2003), p. 331.

6. J.D. Holmes, D.M. Lyons, K.J. Ziegler. Supercritical fluid synthesis of metal and semiconductor nanomaterials. Chem. Eur. J., 9 (2003), p. 2144.

7. S. Desmoulins-Krawiec, C. Aymonier, A. Loppinet-Serani, F. Weill, S. Gorsse, J. Etourneau, F. Cansell. Synthesis of nanostructured materials in supercritical ammonia: nitrides, metals and oxides. J. Mater. Chem., 14 (2004), p. 228.

8. S.T. Oyama. The Chemistry of Transition Metal Carbides and Nitrides. Blackie Academic \& Professional, London (1996).

9. K. Byrappa, T. Adschiri. Hydrothermal technology for nanotechnology. Prog. Cryst. Growth Charact. Mater., 53 (2007), p. 117.

10. H. Reveron, C. Aymonier, A. Loppinet-Serani, C. Elissalde, M. Maglione, F. Cansell. Single-step synthesis of well-crystallized and pure barium titanate nanoparticles in supercriticals fluids. Nanotechnology, 16 (2005), p. 1137.

11. A.R. Bazaev, I.M. Abdulagatov, E.A. Bazaev, A. Abdurashidova. ( $p, v, T, s$ ) measurements of $\left[(1-x) \mathrm{H}_{2} \mathrm{O}+x \mathrm{C}_{2} \mathrm{H}_{5} \mathrm{OH}\right]$ mixtures in the near-critical and supercritical regions. J. Chem. Thermodyn., 39 (2007), p. 385.

12. T. Adschiri, Y. Hakuta, K. Sue, K. Arai. Supercritical hydrothermal synthesis of nanoparticles. J. Nanopart. Res., 3 (2001), p. 227.

13. Erriguible, F. Marias, F. Cansell, C. Aymonier, Monodisperse model to predict the growth of inorganic nanostructured particles in supercritical fluids through a coalescence and aggregation mechanism, J. Supercrit. Fluids (2008), doi:10.1016/j.supflu.2008.09.014.

14. H. Reveron, C. Elissalde, C. Aymonier, M. Maglione, F. Cansell. Continous synthesis of well-crystallized BST nanoparticles under supercritical conditions and its ferroelectric properties. J. Nanosci. Nanotechnol., 5 (10) (2005 1741).

15. H. Reverón, C. Elissalde, C. Aymonier, C. Bousquet, M. Maglione, F. Cansell. Continuous supercritical synthesis and dielectric behaviour of the whole BST solid solution. Nanotechnology, 17 (2006), p. 3527. 
16. M. Atashfaraz, M. Shariaty-Niassar, S. Ohara, K. Minami, M. Umetsu, T. Naka, T. Adschiri. Effect of titanium dioxide solubility on the formation of $\mathrm{BaTiO}_{3}$ nanoparticles in supercritical water. Fluid Phase Equilibria, 257 (2) (2007), p. 233.

17. D. Mesguich, J.M. Bassat, F. Cansell, C. Aymonier, Preparation of a new Nd-Ni based precursor in an alcohol/water supercritical mixture: an original approach to develop $\mathrm{Nd}_{2} \mathrm{NiO}_{4+\delta}$, cathode material for IT-SOFCs, in preparation.

18. Cabañas, J. Li, P. Blood, T. Chudoba, W. Lojkowski, M. Poliakoff, E. Lester. Synthesis of nanoparticulate yttrium aluminium garnet in supercritical water/ethanol mixtures. J. Supercrit. Fluids, 40 (2007), p. 284.

19. Bousquet, C. Elissalde, C. Aymonier, M. Maglione, F. Cansell, J.M. Heintz. Tunability of $\mathrm{Al}_{2} \mathrm{O}_{3}$ crystallinity using supercritical fluid media: effect on sintering. J. Eur. Ceram. Soc., 28 (2008), p. 223.

20. H. Jensen, M. Bremholm, R.P. Nielsen, K.D. Joensen, J.S. Pedersen, H. Birkedal, Y.S. Chen, J. Almer, E.G. Søgaard, S.B. Iversen, B.B. Iversen. In situ high-energy synchrotron radiation study of sol-gel nanoparticle formation in supercritical fluids. Angew. Chem. Int. Ed., 46 (2007), p. 1113.

21. M. Bremholm, H. Jensen, S.B. Iversen, B.B. Iversen. Reactor design for in situ X-ray scattering studies of nanoparticle formation in supercritical water syntheses. J. Supercrit. Fluids, 44 (2008), p. 385.

22. S. Moisan, V. Martinez, P. Weisbecker, F. Cansell, S. Mecking, C. Aymonier. A general approach for the synthesis of organic-inorganic hybrid nanoparticles mediated by supercritical $\mathrm{CO}_{2}$. J. Am. Chem. Soc., 129 (34) (2007), p. 10602.

23. V. Martinez, S. Mecking, T. Tassaing, M. Besnard, S. Moisan, F. Cansell, C. Aymonier. Dendritic core-shell macromolecules soluble in supercritical carbon dioxide. Macromolecules, 39 (2006), p. 3978.

24. S. Moisan, J.D. Marty, F. Cansell, C. Aymonier. Preparation of functional hybrid palladium nanoparticles using supercritical fluids: a novel approach to detach the growth and functionalization steps. Chem. Commun. (2008), p. 1428.

25. R. Jiang, Y. Zhang, S. Swier, X. Wei, C. Erkey, H. Russell Kunz, J.M. Fenton. Preparation via supercritical fluid route of Pd-impregnated nafion membranes which exhibit reduced methanol crossover for DMFC. Electrochem. Solid-State Lett., 8 (11) (2005), p. A611.

26. Sun, R. Zhang, Z. Liu, Y. Huang, Y. Wang, J. He, B. Han, G. Yang. Polypropylene/silica nanocomposites prepared by in situ sol-gel reaction with the aid of $\mathrm{CO}_{2}$. Macromolecules, 38 (2005), p. 5617.

27. S. Marre, F. Cansell, C. Aymonier. Tailor made surface properties of particles with a hydrophilic or hydrophobic polymer shell mediated by supercritical $\mathrm{CO}_{2}$. Langmuir, 24 (1) (2008), p. 252.

28. K.J. Ziegler, R.C. Doty, K.P. Johnston, B.A. Korgel. Synthesis of organic monolayer-stabilized copper nanocrystals in supercritical water. J. Am. Chem. Soc., 123 (2001), p. 7797.

29. T. Adshiri. Supercritical hydrothermal synthesis of organic-inorganic hybrid nanoparticles. Chem. Lett., 36 (10) (2007), p. 1187.

30. Y. Zhang, C. Erkey. Preparation of supported metallic nanoparticles using supercritical fluids: a review. J. Supercrit. Fluids, 38 (2006), p. 252.

31. S. Marre, F. Cansell, C. Aymonier. Design at the nanometer scale of multifunctional materials using supercritical fluid chemical deposition. Nanotechnology, 17 (2006), p. 4594.

32. S. Marre, A. Erriguible, A. Perdomo, F. Cansell, F. Marias, C. Aymonier, Kinetically-controlled formation of supported nanoparticles in low temperature supercritical media for the development of advanced nanostructured materials, in preparation.

33. J.L. Bobet, C. Aymonier, D. Mesguich, F. Cansell, K. Asano, E. Akiba. Particle decoration in supercritical fluid to improve the hydrogen sorption cyclability of magnesium. J. Alloys Compd., 429 (2007), p. 250. 
34. Y. Zhang, B. Cangul, Y. Garrabos, C. Erkey. Thermodynamics and kinetics of adsorption of bis(2,2,6,6tetramethyl-3,5-heptanedionato)(1,5-cyclooctadiene) ruthenium (II) on carbon aerogel from supercritical $\mathrm{CO}_{2}$ solution. J. Supercrit. Fluids, 44 (2008), p. 71.

35. Y. Zhang, D. Kang, M. Aindow, C. Erkey. Preparation and characterization of ruthenium/carbon aerogel nanocomposites via a supercritical fluid route.J. Phys. Chem., 109 (2005), p. 261.

36. Z. Sun, Z. Liu, B. Han, S. Miao, Z. Miao, G. An. Decoration carbon nanotubes with Pd and Ru nanocrystals via an inorganic route in supercritical carbon dioxide-methanol solution. J. Colloids Interface Sci., 304 (2) (2006), p. 323.

37. S. Miao, C. Zhang, Z. Liu, B. Han, Y. Xie, S. Ding, Z. Yang. Highly efficient nanocatalysts supported on hollow polymer nanospheres: synthesis, characterization and applications. J. Phys. Chem. C, 112 (2008), p. 774.

38. M. Chatterjee, Y. Ikushima, Y. Hakuta, H. Kawanami. In situ synthesis of gold nanoparticles inside the pores of MCM-48 in supercritical carbon dioxide and its catalytic application. Adv. Synth. Catal., 348 (2006), p. 1580.

39. O'Neil, J.J. Watkins. Fabrication of device nanostructures using supercritical fluids. MRS Bull., 30 (2005), p. 967.

40. O'Neil, J.J. Watkins. Reactive deposition of conformal ruthenium films from supercritical carbon dioxide. Chem. Mater., 18 (2006), p. 5652.

41. O'Neil, J.J. Watkins. Reactive deposition of conformal metal oxide films from supercritical carbon dioxide. Chem. Mater., 19 (2007), p. 5460.

42. Aymonier, C. Elissalde, H. Reverón, F. Weill, M. Maglione, F. Cansell. Supercritical fluid technology of nanoparticles coating for new ceramic materials. J. Nanosci. Nanotechnol., 5 (2005), p. 980.

43. Z. Sun, X. Zhang, B. Han, Y. Wu, G. An, Z. Liu, S. Miao, Z. Miao. Coating carbon nanotubes with metal oxides in a supercritical carbon dioxide-ethanol solution. Carbon (N. Y.), 45 (13) (2007), p. 2589.

44. R.A. Pai, J.J. Watkins. Synthesis of mesoporous organosilicate films in supercritical carbon dioxide. Adv. Mater., 18 (2006), p. 241.

45. V.R. Tirumala, R.A. Pai, S. Agarwal, J.J. Testa, G. Bhatnagar, A.H. Romang, C. Chandler, B.P. Gorman, R.L. Jones, E.K. lin, J.J. Watkins. Mesoporous films with long-range order prepared from strongly segregated block copolymer/homopolymer blend templates. Chem. Mater., 19 (2007), p. 5868.

46. J.P. Hanrahan, M.P. Copley, K.J. Ziegler, T.S. Spalding, M.A. Morris, D.C. Steyler, R.K. Heenan, R. Schweins, J.D. Holmes. Pore size engineering in mesoporous silicas using supercritical $\mathrm{CO}_{2}$. Langmuir, 21 (2005), p. 4163.

47. Y. wang, Z. Liu, B. Han, Z. Sun, J. Du, J. Zhang, T. Jiang, W. Wu, Z. Miao. Replication of biological organizations through a supercritical fluid route. Chem. Commun. (2005), p. 2948.

48. Z. Miao, K. Ding, T. Wu, Z. liu, B. Han, G. An, S. Miao, G. Yang. Fabrication of 3D-networks of native starch and their application to produce porous inorganic oxide networks through a supercritical route. Microporous Mesoporous Mater., 111 (2008), p. 104.

49. J. Xu, W. Zhang, M.A. Morris, J.D. Holmes. The formation of ordered bismuth nanowire arrays within mesoporous silica templates. Mater. Chem. Phys., 104 (2007), p. 50.

50. H.Y. Tuan, B. Korgel. Importance of solvent-mediated phenylsilane decomposition kinetics for high-yield solution-phase silicon nanowire synthesis. Chem. Mater., 20 (2008), p. 1239.

51. H.Y. Tuan, A. Ghezelbash, B. Korgel. Silicon nanowires and silica nanotubes seeded by copper nanoparticles in an organic solvent. Chem. Mater., 20 (2008), p. 2306.

52. Yoo, A. Dodabalapur, D.C. Lee, T. Hanrath, B.A. Korgel. Germanium nanowire transistors with ethylene glycol treated poly(3,4-ethylenedioxythiophene):poly(styrene sulfonate) contacts. Appl. Phys. Lett., 90 (2007), p. 072106. 
53. H.Y. Tuan, D.C. Lee, B.A. Korgel. Nanocrystal-mediated crystallization of silicon and germanium nanowires in organic solvents: the role of catalysis and solid-phase seeding. Angew. Chem. Int. Ed., 45 (2006), p. 5184.

54. N. Petkov, P. Birjukovs, R. Phelan, M.A. Morris, D. Erts, J.D. Holmes. Growth of ordered arrangements of onedimensional germanium nanostructures with controllable crystallinities. Chem. Mater., 20 (2008), p. 1902.

55. Z. Lou, Q. Chen, W. Wang, Y. Zhang. Carbon (N.Y.), 41 (2003), p. 3063.

56. D.K. Smith, D.C. Lee, B.A. Korgel. High yield multiwall carbon nanotube synthesis in supercritical fluids. Chem. Mater., 18 (2006), p. 3356.

57. Z. Li, J. Andzane, D. Erts, J.M. Tobin, K. Wang, M.A. Morris, G. Attard, J.D. Holmes. A supercritical-fluid method for growing carbon nanotubes. Adv. Mater., 19 (2007), p. 3043. 
Figures :

Chemical transformation of metal precursor in supercritical fluids

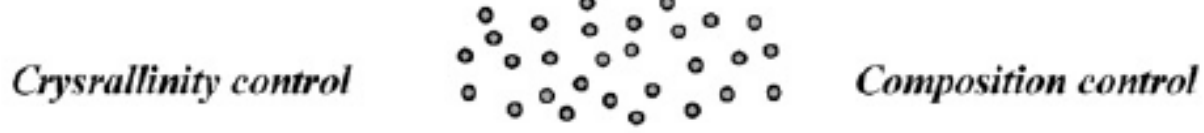

Nanopowders of oxides, metals,

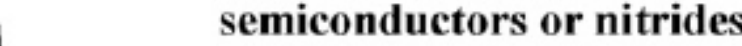

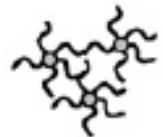

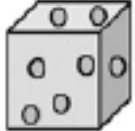

Supported nanoparticles

Polymer impregnation coating
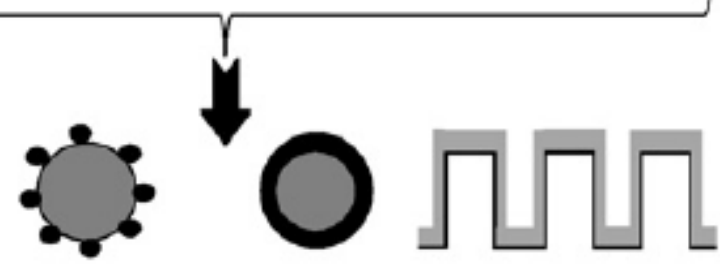

Core - Conformational Nanowires,

Shell film Nanorods,

Hybrid nanostructured materials Inorganic nanostructured materials

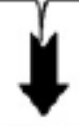

Functional nanostructured materials

Fig. 1. Functional nanostructured materials starting from a metal precursor. 


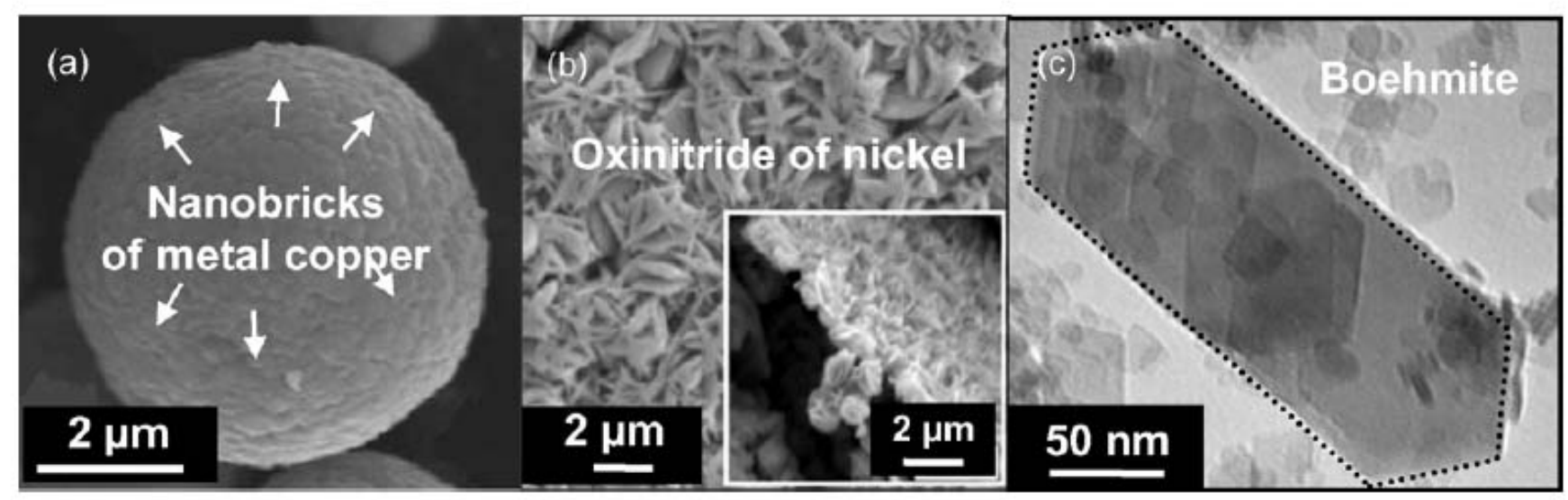

Fig. 2. Control of material nature with the choice of the solvent: (a) nanostructured particle of metal copper in $\mathrm{scCO}_{2}$, (b) self-assembled flowers of oxinitride of nickel in scNH3, (c) nanocrystals of boehmite in $\mathrm{scH}_{2} \mathrm{O}$. 


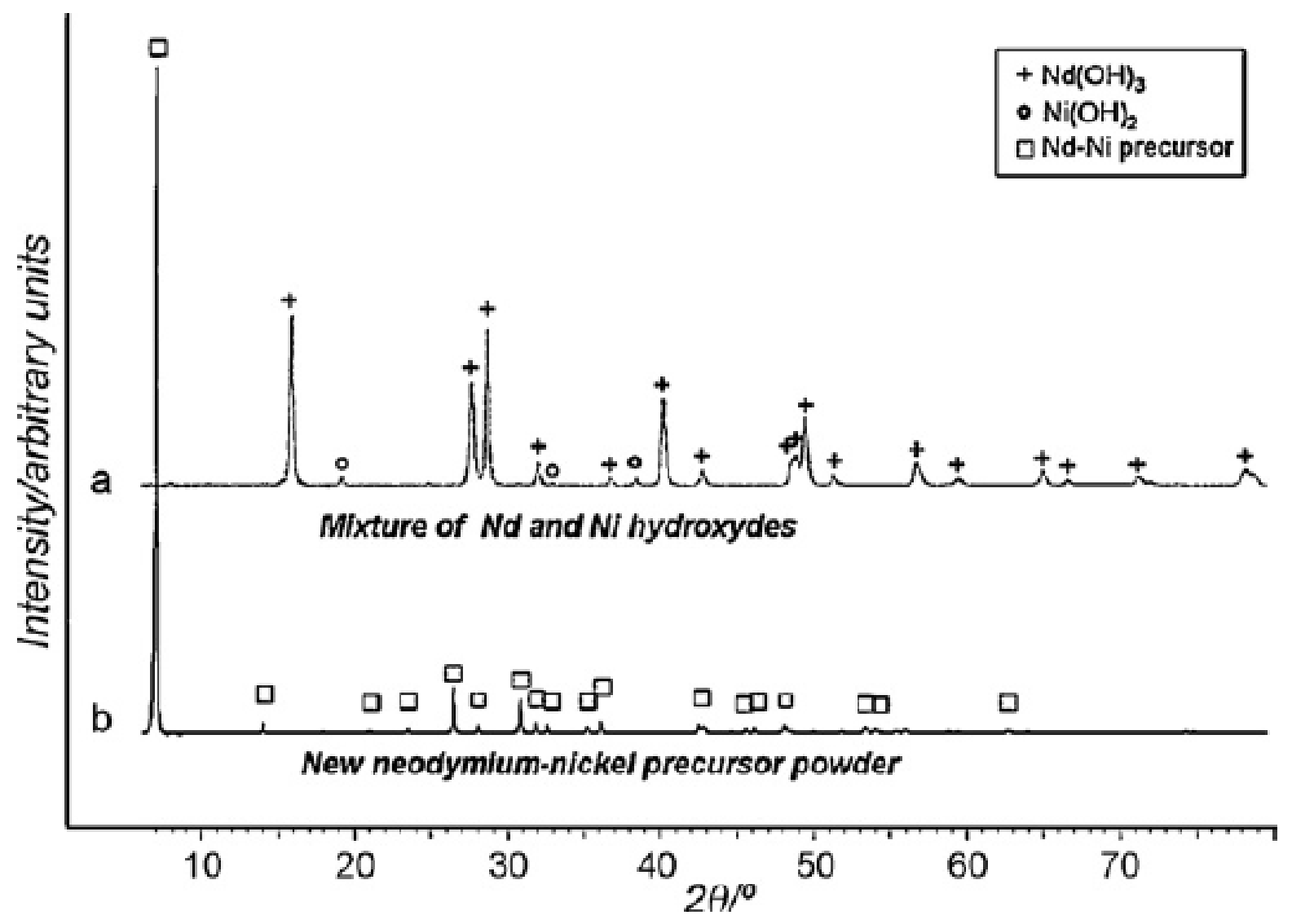

Fig. 3. X-ray powder diffraction patterns of powders elaborated at $290^{\circ} \mathrm{C}$ and $20 \mathrm{MPa}$ with two different ethanol/water molar ratios: (a) 0/100 and (b) 90/10. 


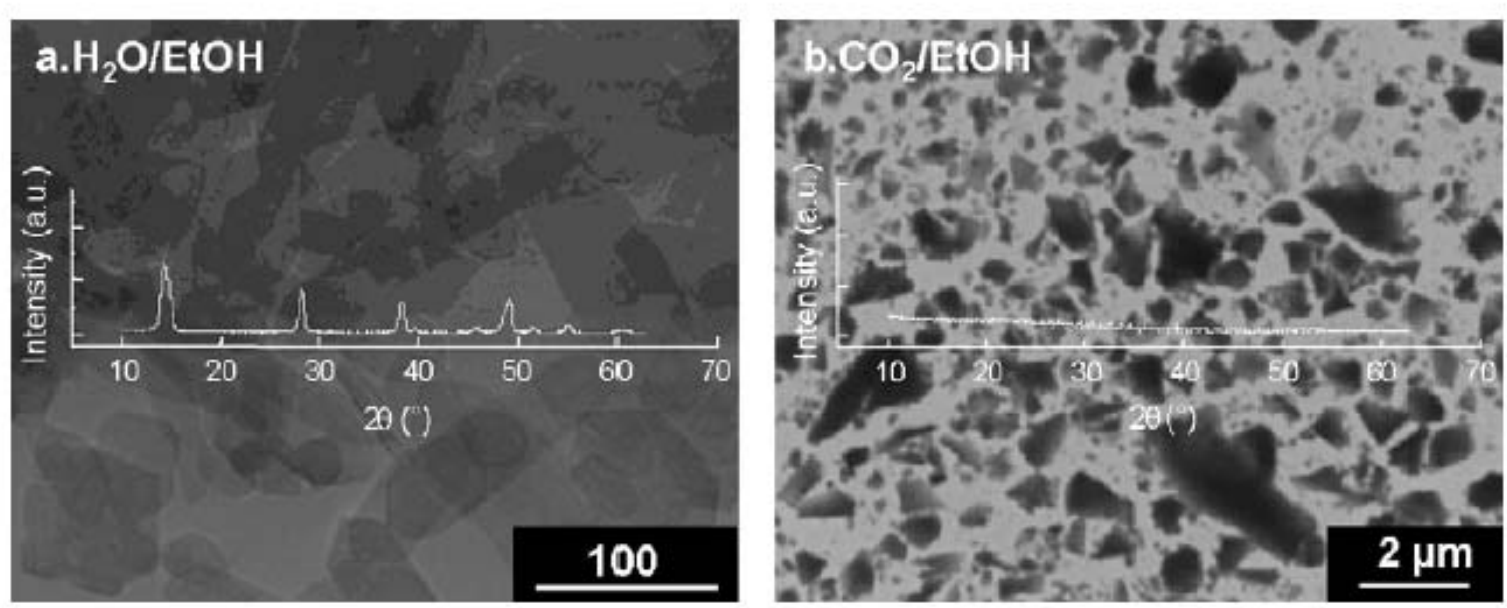

Fig. 4. Tuning of crystallinity rate of alumina powders with the fluid nature: (a) XRD pattern and TEM image of boehmite nanoparticles formed in a $\mathrm{H}_{2} \mathrm{O} / \mathrm{EtOH}$ mixture, (b) $\mathrm{XRD}$ and SEM image of amorphous alumina synthesized in $\mathrm{scCO}_{2} / \mathrm{EtOH}$ mixture. 


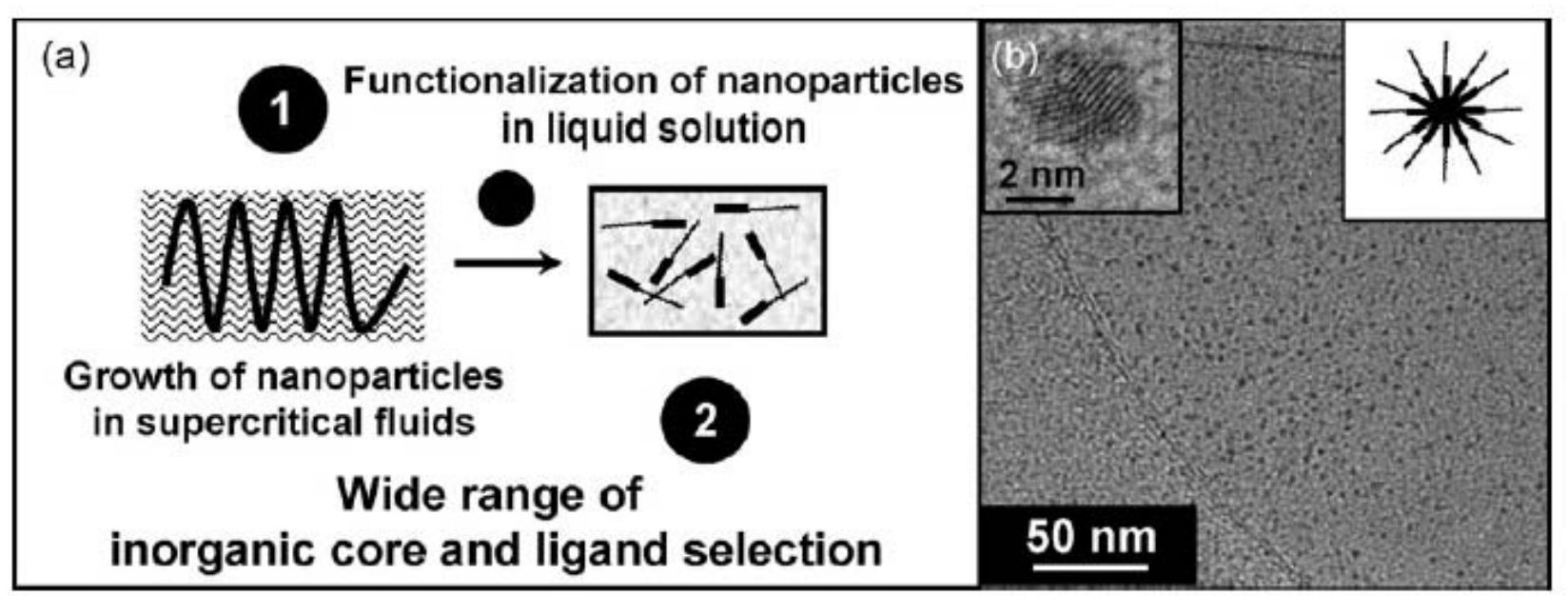

Fig. 5. (a) Illustration of the synthesis method of functional nanoparticles based on the separation of growth and functionalization steps, (b) TEM image of BMIMPF6 functionalized palladium nanoparticles (as insert on the left: HRTEM image of a well-crystallized palladium nanoparticle, as insert on the right: scheme of a functionalized palladium nanoparticle). 

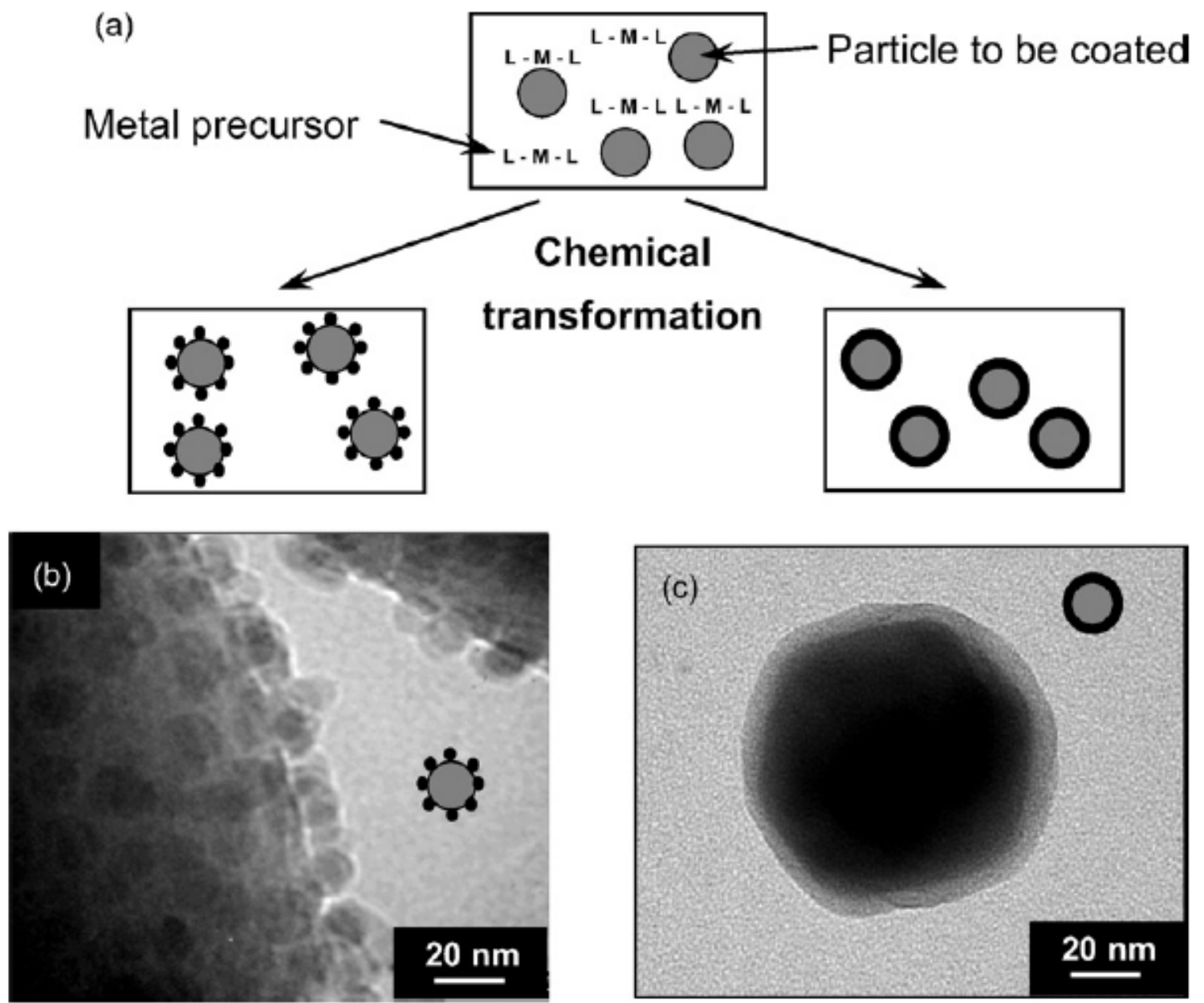

Fig. 6. Nanoengineering of material surface: (a) principle of the supercritical fluid chemical deposition process (SCFD), (b) TEM image of supported nanoparticles of metal copper on silica spheres and (c) TEM image of a $\mathrm{BaTiO}_{3}$ nanoparticle coated with an amorphous alumina shell. 